ISSN: $1130-3743$

\title{
ARTE, MÚSICA Y PERFECCIÓN EN LA SOCIEDAD GLOBAL
}

\author{
Art, music and perfection in the global society
}

Art, musique et perfection dans la société globale

Sagrario MARTínez BERRIEL

Universidad de Salamanca. Facultad de Ciencias Sociales. Departamento de Sociología y Comunicación. Campus Miguel de Unamuno-Edificio FES. Avda.

Francisco Tomás y Valiente, s/n. 37071 Salamanca. Correo-e: smberriel@usal.es

Fecha de recepción: marzo de 2013

Fecha de aceptación: junio de 2013

Biblid [(1130-3743) 25, 2-2013, 89-109]

RESUMEN

El artículo analiza la renovada importancia del significado trascendente de la cultura, entendida como ideal de perfección, en la construcción de la sociedad global, haciendo referencia al papel social del arte en la convivencia, educación y comunicación del nuevo orden mundial. Deteniéndose en la música en un sentido más concreto y analítico, como espacio predilecto y vital de afirmación de la armonía y el entendimiento universal, al mismo tiempo que en los músicos como representantes cualificados de este ideal.

Palabras clave: cultura, perfección, arte, música, armonía mundial. 
SUMMARY

The article analyses the renewed importance of culture's transcendent meaning, as perfection, as understood in the context of globalisation, making reference to the social role played by art and more poignantly by music and classical musicians, as the chosen and preffered area of stating a universal cultural ideal.

Key words: culture, perfection, art, music, world harmony.

\section{SOMMAIRE}

L'article analyse l'importance renouvelée du sens transcendant de la culture, entendue comme perfection, dans le contexte de la globalisation, en faisant référence au papier social joué par l'art et d'une manière plus pointue par la musique et les musiciens classiques comme espace préféré de son affirmation.

Mots clés: culture, perfection, art, musique, harmonie mondiale.

\section{INTRODUCCIÓN}

El arte y más aún la música, por su inmaterialidad, ocupan un lugar marginal tanto en la educación como en la investigación de las ciencias sociales, lo que se debe a una afianzada concepción materialista de la cultura que estima secundario el papel del arte en cuanto al sostenimiento y funcionamiento de la sociedad. Este presupuesto viene avalado por la consideración del arte como un dominio estético propio, gobernado por categorías "asociales" como la espiritualidad, la singularidad y el gusto. Contrariamente a este modo de pensar, el propósito de este trabajo es demostrar la importancia que tiene para todo el sistema social la dimensión trascendente de la cultura, no sólo como dominio legítimo del arte en paralelo o sustitución de la religión, sino como núcleo duro de su permanente significado a lo largo de la historia de la humanidad.

En efecto, en el origen del concepto de cultura late un sentido de "idealidad", de finalidad del ser humano tanto a nivel individual como de género. Como arte y parte de la naturaleza que somos, compartimos con ella la fertilidad y por tanto la capacidad de mejorarnos gracias al cultivo de nuestras facultades físicas y espirituales (Hell, 1986). Este punto de partida explica la dualidad etimológica del significado de la cultura, por un lado referido a la práctica religiosa y por otro al cultivo de la tierra y de nosotros mismos. De acuerdo con esta bipolaridad presente en la "sociología vitalista" de Simmel (Lebenssoziologie), "la perfección" como universal palpitar de la vida es la esencia de la cultura de todos los tiempos. Karl Polanyi adopta este mismo argumento en su obra clásica de la antropología económica sobre los orígenes políticos de nuestro sistema económico. En ella 
sostiene: "la pulcritud en el trabajo", el "hacer las cosas bonitas" y "disfrutar de la obra" son rasgos esenciales de aprobación social que se repiten desde los primeros tiempos de la "economía primitiva" (1992, cap. vi).

La perspectiva teórica de esta investigación es complementaria a la que ha sido más habitual en la reciente sociología del arte (Heinich, 2001; Zolberg, 2002) deudora de la obra de Bourdieu y caracterizada por "desidealizar" el arte, es decir, por demostrar que éste no es puro ni desinteresado sino que está determinado por factores materiales ajenos a él mismo. Aunque este trabajo no niega la validez y riqueza de la aludida visión desmitificadora, su atención gravita sobre la intrínseca necesidad humana de trascender y crear bienes de admiración imperecederos: jel arte por el arte! como finalidad sin utilidad. Su objeto por tanto consiste en analizar la importancia de la dimensión trascendente de la cultura en la reciente modernidad y a partir de este argumento explicar la expansión del idealismo a toda la organización social, lo que supone la preeminencia de una sociedad dominada por el arte, en la que éste, además de ser la materia prima y "viva" de la innovación y de los medios de comunicación de masas, asume la condición de principio laico de espiritualidad y convivencia mundial.

\section{De los Significados de la CUltura}

La noción de cultura es extremadamente amplia, difusa y contradictoria (Cuché, 1998), concilia múltiples conceptos que, aun no siendo necesariamente opuestos, han funcionado como tales: naturaleza-artificio, totalidad-particularidad, idealismoempirismo, lo aprendido frente a lo biológico, lo racional frente a lo irracional, etc., y además plantea niveles de representación muy diversos, como individuo, comunidad y humanidad. Pese a todo ello, no existe idea más prolífica y necesaria en el uso común y en las ciencias sociales. De los múltiples significados que acompañan la compleja y "viva" idea de cultura, Raymond Williams (1974) destaca tres modernas acepciones: 1. Cultura es el proceso (o procesos) de desarrollo moral, intelectual y estético de la humanidad. 2. Cultura son los modos de vida de un pueblo, de un grupo o de la humanidad en su conjunto. 3. Cultura son las prácticas del arte y de la inteligencia. En este elenco se distinguen dos corrientes de pensamiento beligerantes que lideraron Francia y Alemania durante el siglo de las Luces y el Romanticismo. Una, heredera de la Revolución francesa, considera la cultura objetivamente y en sentido universal como progreso material y de ilustración de la humanidad. La otra, a contracorriente y liderada por el idealismo alemán, entiende por cultura, la "Bildung", la formación moral, intelectual y estética como finalidad del hombre. Esta segunda acepción será la que tome especial relevancia con el Romanticismo europeo, movimiento social receloso de las consecuencias del progreso al que atribuye la marginación del arte y la poesía al cumplimiento de tareas utilitarias. Lo que explica su cruzada en favor del significado plural de la cultura intimista y popular en oposición a la cultura "educada", al mismo tiempo 
que el reconocimiento del arte como vía de emancipación y trascendencia del ser humano.

El conflicto entre estas dos concepciones de la cultura hasta cierto punto se salda tras la Segunda Guerra Mundial, adoptando como norma de educación y convivencia política a nivel nacional e internacional un significado antropológico y plural de la cultura, entendida ésta como la forma de vida distintiva y total de los pueblos y de las sociedades. Sin embargo, según avanza el siglo y con él el nuevo orden mundial "postcolonial" (Bhaba, 1994), la compleja realidad social emergente resulta inabarcable por el concepto que pretendía explicarla. Así, en efecto, la influencia de los medios de comunicación de masas, de los movimientos sociales globales como el feminismo y el ecologismo, y el despertar de diversas minorías marginadas por causas como la religión, la etnia o las preferencias sexuales han obligado a ensanchar y diversificar el significado de cultura de modo que resulte acorde con el mestizaje, la hibridación y la globalización. En consecuencia, el concepto en la actualidad genera más preguntas que las que resuelve, de ahí que según Denys Cuché (1998) sería conveniente volver a un término más preciso y restrictivo.

La eclosión de la diferencia como valor social, junto con el hecho de que todo pretende ser cultura, produce desconcierto entre los estudiosos de las ciencias sociales. Así, se aduce, por ejemplo, que resulta casi imposible encontrar unos principios comunes sobre los que construir un entendimiento universal (Luque, 1974, 2004). Y que la cultura a fuerza de ser tan "omnicomprensiva" se torna incoherente e incapaz de prescribir y enjuiciar lo que está bien o mal, es bello o feo, bueno o malo, lo que resulta perjudicial para todos. Estas críticas en cierto modo conservadoras muestran el anhelo de volver a llamar a las cosas por su nombre para evitar la confusión "democrática" de que todo es igual y cultural sin distinción de lugar, clase o escala, ignorando por ejemplo el profundo abismo que separa a la cultura de masas de la alta cultura. Contrariamente a este punto de vista prospera la convicción de que los conceptos estáticos son de por sí inútiles para explicar las realidades móviles de nuestro tiempo que obedecen a flujos y redes. Desde esta perspectiva, las culturas se consideran sometidas a un intenso proceso de "hibridación", consecuencia de la circulación de bienes, mensajes y personas de modo que "todas son de frontera". Lo que es propio de la cultura, por tanto, es la "hibridación" en todos los sentidos: el trasiego continuo entre lo vulgar y lo trascendental, lo elitista y lo común, lo local y lo extranjero (García Canclini, 2003). Incluso, el hoy y el ayer como plantea Bruno Latour porque somos "politemporales" y no se puede disponer de un metarrelato en el que ordenar y jerarquizar las proezas de la humanidad según una línea ascendente (Latour, 1993, 111-115). Esta convicción precisamente de ausencia de dirección en la historia de la humanidad y de superposición de tiempos en un mismo espacio es uno de los argumentos centrales en la definición de la llamada postmodernidad, lo que explica, como se analizará más adelante en esta exposición, el renovado interés por el mito y el "reencantamiento del mundo". 
Por encima de la imprecisión y contradicción del concepto de cultura anteriormente comentado, existe en toda la modernidad -tanto si nos consideramos después de ella o parte de ella- un endémico sentimiento negativo acerca de su valor como cauce de entendimiento con la naturaleza, con nosotros mismos y con los demás. En este sentido, como señala Arthur Herman (1998), la ideología política predominante del pensamiento occidental moderno es el "pesimismo cultural". La sombría y profética reflexión de Oswald Spengler en La decadencia de Occidente, siguiendo a Nietzsche, de que la sociedad europea está enferma y se dirige a su destrucción es el lugar común por excelencia de los «intérpretes de la cultura moderna". Abundando en este mismo planteamiento, no está de más recordar que la fatalidad de la cultura forma parte de las dos teorías sociales más influyentes de la modernidad: el marxismo y el psicoanálisis y que ambas teorías comparten la convicción de que hay que liberar a la humanidad de la irracionalidad y la fe. Pues bien, a pesar de la hegemonía de esta forma de pensamiento y el consecuente "malestar en la cultura" como planteó Freud, la lección de la historia parece demostrar que, por encima de la ciencia y de la técnica, el sentido trascendente de la existencia humana no encuentra consuelo en explicaciones racionales. Es más, la racionalización del mundo va inextricablemente acompañada de un creciente fanatismo religioso e identitario. Incluso en las sociedades "más avanzadas" se constata un creciente proceso de "sacralización de lo profano" (Giner, 2005), de modo que el escaso apoyo de las religiones oficiales se compensa con un amplio elenco de prácticas sociales como el deporte, la música o el turismo vividas con entusiasmo religioso.

\section{De la CUltura COMO «PERFECCióN"}

Simmel, haciéndose eco de un ideal trascendente y universal de la cultura, válido en todo tiempo y lugar, afirma que es esencia de la cultura "consumar" la perfección, una tendencia innata de la que participa el individuo y la humanidad. Citando sus palabras: "Sólo el hombre es el auténtico objeto de la cultura; pues él es el único ser que nos es conocido en el que reside de antemano la exigencia de una perfección" (Simmel, 1999, 121). "Cultivar" y "cultivarse" (un árbol o una persona) significa en su planteamiento añadir a la naturaleza un principio de voluntad ajeno a sus propias predisposiciones gracias al cual ésta consigue superarse y llegar más allá de lo que en ella era natural. Es gracias al quehacer humano que se logra dicha ascensión, pero su posibilidad radica en una tendencia inscrita en toda la naturaleza.

Simmel atribuye desde este punto de vista una preocupación de primer orden a la finalidad de la cultura: un proceso en el que la vida se enfrenta permanentemente a las formas que crea, porque éstas, en su tendencia a cristalizarse, no pueden avanzar con ella restándole vitalidad. Ésa es precisamente la "tragedia" de la cultura, la vida desea trascender las formas y aparecer en su desnuda inmediatez, pero su anhelo es inalcanzable (Ramos, 2000). Además, existe un inevitable desfase entre 
la cultura objetiva y la subjetiva: "Las disonancias de la vida moderna surgen en gran medida del hecho de que ciertamente las cosas se tornan cada vez más cultivadas, pero los hombres sólo en una medida mínima están en condiciones de alcanzar a partir de la perfección del objeto una perfección de la vida subjetiva" (Simmel, 1999-125). De esta concepción vitalista de la cultura cabe destacar los siguientes argumentos:

1. La perfección es una pulsión original de la humanidad.

2. Cultura y naturaleza son dos modos de considerar un mismo e indivisible acaecer.

3. Los medios que utilizamos para trasformar la naturaleza proceden de ella misma.

4. La cultura es síntesis y superación de los conceptos de sujeto y objeto.

5. La cultura es trascendencia, desarrollo de nuestra totalidad como unidad.

6. Los humanos somos toscos aprendices de la perfección que sin embargo creamos.

En la burbujeante vitalidad humana late el sentido de la cultura que no es otro en definitiva que mejorar la vida pero también vivir y estar vivo, fluir sin término, pasar el tiempo. Porque la vida se manifiesta de dos maneras complementarias entre sí: como "más-vida" y como "más-que-vida" (Simmel, 2000, 309). Se trata de un proyecto de "perfección" trascendente, porque la aspiración de la vida tiene que ver con la eternidad, pero también intrascendente, porque nada permanece. Por ello precisamente esta meta en el ser humano es un medio de identificación, de unificación entre sujeto y objeto para escapar al fluir del tiempo. Siguiendo este punto de vista del que se hace eco la Lebenssoziologie (Lash, 2003) y admitiendo por tanto la perfección como superación de la dualidad entre cultura y vida, la pregunta concreta que guía este artículo es cuál es y dónde está el sentido de la perfección en nuestra cultura y, por extensión, en qué medida este argumento sigue siendo una búsqueda individual y colectiva que sirve como principio de entendimiento universal.

El meollo de este debate remite a la perfección como sinónimo del ideal trinitario clásico constituido por la verdad, la belleza y el bien, como eternos e inmutables valores universales. Hanna Arendt en La Condición humana explica muy bien el trasfondo de este sistema armónico: ante el telón de fondo de la siempre repetida vida de la naturaleza y de la existencia igualmente sin muerte ni edad de los dioses, se erigen los hombres mortales, únicos mortales en un inmortal universo. La única grandeza posible para ellos radica en producir trabajos, actos y palabras que merezcan ser imperecederos para escapar al tiempo y a la inevitable caducidad de la vida humana que camina hacia la muerte. Tal es el propósito universal al que responden el arte y la vida contemplativa. Siguiendo su argumentación, la secularización, la inversión del valor de la acción frente a la contemplación y el interés por las cosas de este mundo como rasgos determinantes 
de la Edad Moderna no han eliminado del ser humano esta pulsión trascendente (2005, 43-46). La voluntad de escapar al tiempo late en el centro de nuestra cultura, incluso en la propia ciencia, cuyo propósito no es otro que escapar de la Tierra y de la condición humana (ibídem, 29-34). El filósofo George Steiner (1975) plantea una reflexión paralela a la de Hanna Arent de enorme interés para lo que estamos discutiendo. En su opinión, la crisis de la cultura contemporánea se resume en un sentimiento de "nostalgia del absoluto" porque la cultura ha fracasado en cuanto a dar sentido de totalidad al individuo en su relación con el mundo: sentido de integridad, de finalidad de la historia y de justicia moral.

De acuerdo con estos planteamientos filosóficos, la postmodernidad se concibe como la vuelta al mito frente al descrédito de la razón. No es casual por ello, en este contexto, el interés que despiertan en la investigación actual de las ciencias sociales la intuición, la imaginación y el "reencantamiento del mundo" (Maffessoli, 1997; Lenoir, 2003). El discurso se corresponde con la evidencia en la vida cotidiana de un pujante sentido de espiritualidad, de atención a la vida sentimental y a la educación emocional, lo que sin duda guarda directa correspondencia con el "empoderamiento" femenino y la mayor visibilidad del mundo afectivo de las mujeres (Martínez Berriel, 2011). Este hecho es particularmente visible en el contenido del arte y en su influencia social a través de géneros de gran consumo como el realismo mágico de la literatura, la música mística, el cine de ficción mitológica. Además, se pueden citar incontables prácticas sociales teñidas de un sentimiento "religioso", aunque, eso sí, fuera de la experiencia institucional de las religiones oficiales. En todos los órdenes de la vida, se puede afirmar que desde el ámbito más íntimo al contexto más universal proliferan creencias "sagradas" y "mágicas" resultado de una heterodoxa y sincrética mezcla de conocimientos y experiencias alternativas cuyo origen se pierde en la noche de los tiempos. Saberes de muy variada procedencia en el tiempo y el espacio, tales como la agricultura biológica, la homeopatía, el yoga y un largo etcétera, con utilidades hasta cierto punto desacralizadas por su nueva ubicación a nivel de órden práctico. Lo más característico de esta tendencia "espiritualizante" es su dimensión "holística", un esfuerzo por superar las falsas dualidades y escisiones que la cultura occidental ha hecho ley tales como, mente/ cuerpo, naturaleza/cultura y microcosmos/macrocosmos.

Siguiendo este razonamiento, el análisis sociológico del profuso clima trascendente y holístico que acapara el conocimiento y la sociedad induce a considerar "la perfección" en un sentido absoluto: cognitivo, ético y estético, como la definición de cultura que pugna por aglutinar los múltiples significados del concepto en la reciente modernidad. Desde ese punto de vista, resulta fundamental detenerse en el papel social del arte. Un espacio social, privilegiado, históricamente en cuanto a garantizar y cultivar la educación de los valores que han sido su especialidad ontológica: la originalidad, la autenticidad y la espiritualidad.

La emergente espiritualidad a la que nos referimos se expresa como un proceso creciente de "estetización" y "moralización" de la vida social, lo que supone traspasar la estricta materialidad y el materialismo que ésta comporta. Este 
mecanismo puede incluirse de forma más general en la teoría de la "revolución silenciosa" que propone Inglehart según la cual la sociedad global es portadora del avance de los "valores post-materialistas" (Inglehart, 1991). Junto a ella se manifiesta la hegemonía de una "élite transnacional" de vocación universal que exalta el valor del arte como principio de identidad, tanto a nivel individual de "vivir con arte", como global de promover en todo el mundo su dominio (Martínez Berriel, 2008). Reflejo de estos cambios globales son los comentarios y eslóganes, especialmente visibles en la publicidad mediática, que inciden en concienciar a la sociedad sobre la inadecuada correspondencia entre medios y fines y sobre la responsabilidad ética que tenemos en todos los ámbitos de la existencia, empezando por nosotros mismos y acabando por el cambio climático.

\section{DEL ARTE COMO PERFECCIÓN Y VITALIDAD DE LA CULTURA}

Como se ha afirmado en otro momento de la exposición, en teoría se ha adoptado de manera generalizada un significado de cultura antropológico, pero, en la práctica (especialmente en los medios de comunicación), el valor de la cultura remite al mundo de las artes y los artistas. La dualidad y confusión que este hecho entraña es una prueba del profundo descontento que reina en la cultura. ¿A qué se debe la confusión entre arte y cultura? ¿Por qué los medios de comunicación alimentan esta confusión e identifican a su vez cultura con ocio?

Según Eagleton, considerar el arte como el ámbito "culto" de la cultura limita la perfección a un mundo "Sagrado" ajeno a la realidad a la vez que cerrado en sus propias normas, del que participa una escasa proporción de la población, lo que denota que los valores "civilizados" sólo pueden ser alcanzables a través de la fantasía (Eagleton, 2001, 32). ¿Debemos entender acaso que no es perfectible toda nuestra existencia social?, o ¿es que ya no existe tal proyecto? La respuesta cuando menos es dudosa, sea ateniéndonos a la devaluación del arte como espacio de evasión, sea constatando la debilidad de las culturas locales y "la conversión de la identidad en un próspero valor de mercado" (Moreno, 2005). ¿En qué momento la integridad moral y el conocimiento empírico se hicieron independientes?, ¿cómo ha ocurrido este proceso? De acuerdo con Gellner (1992), en la Modernidad la cultura se fractura en campos de interés autónomos (política, cultura, mercado); de este modo, producir cosas bellas y espirituales, no necesarias ni útiles, acabó siendo un ejercicio de imaginación privado o de entretenimiento público. Es por ello que, como señala Norbert Elias, en El Proceso de Civilización: ser civilizados no ha significado ser más perfectos (ni más íntegros) sino tener más autocontrol sobre las emociones, desviando las pasiones y los sentimientos de la vida pública a la vida privada y al espacio imaginario del arte y el deporte (Elias, 1987). Así, a la vez que se rompe la coherencia de un mundo espiritual obligatorio y unitario, compartido por todos, el arte como dominio de lo excelso asume la función de "religión laica" (Ramírez, 1998). No es raro por ello que uno de los significados predominantes de la palabra cultura sea precisamente el de arte. 
Retrocediendo a la Antigüedad, la función social del arte era otra y "total": Hannah Arent, en La condición bumana, califica el arte de la Polis como "pensamiento puro" e "inútil" que aspira a permanecer; por ello, en tanto que algo inmortal y único, realizado por manos mortales, desafía el principio del intercambio (2005, 189). Este presupuesto filosófico del arte como espacio "sagrado", cerrado en las paredes de su historia y sin otra obligación que referirse a sí mismo, quedó con la Modernidad transformado en un ideal de autonomía particularmente afianzado por el Romanticismo. Ello ha permitido al arte llevar más lejos que ninguna otra experiencia humana el principio de la libertad, hasta el punto incluso de identificarse con ella. En este sentido, Oscar Wilde decía muy acertadamente en el prefacio El retrato de Dorian Gray (1890): "Todo arte es completamente inútil: No importa el contenido sino la forma, no importa la moral, ni la educación sino la belleza, vicio y virtud son materiales del arte" (Wilde, 1983, 6). En su condición de inútil y desinteresado, el arte ha cultivado el vital e ininterrumpido principio del riesgo y la novedad haciendo realidad la afirmación de Shelling: "... donde está el arte, allí aún debe llegar la ciencia". Precisamente siguiendo esta aseveración, Daniel Bell (1971) afirma que el arte ocupa una misteriosa función de vanguardia espiritual, promoviendo, con mayor eficacia incluso que la tecnología, el cambio social y la dinamización del futuro (Bell, 1971, 45-47).

Hasta cierto punto -más como ideología que como realidad, desde luegosin comprometerse con ninguna finalidad política ni deberse a las obligaciones del mercado, el arte ha experimentado con fruición los límites de la libertad, de la cordura y de la moral. Lo que por supuesto no significa que su dominio (el artista, la obra, el público, las condiciones y los espacios de recepción) sea políticamente neutral ni que su existencia vague por encima de las realidades mundanas y extraeconómicas, pero sí que su valor en tanto que experiencia ética y estética escapa a las consideraciones materiales. Gracias a esa posición autónoma, el arte ha logrado ser, en la acepción de Simmel, el recurso por excelencia más vital de la cultura.

La consideración del arte como el espacio más "vital" de la cultura, como la máxima expresión de "la intensidad de la vida", fue un argumento desarrollado por Jean Marie Guyau a finales del siglo XIX, en una de las primeras obras reconocidas como sociología del arte. Desde su consideración, no exenta de controversia, la experiencia estética se fundamenta en la "simpatía": una forma de solidaridad y atracción interindividual basada en la permeabilidad del sujeto a las influencias de los otros sujetos (Serravezza, 1980). Su argumento fue recogido algunas décadas después, a principios de los años 20 del siglo xx, por Ortega y Gasset en La deshumanización del arte, donde afirma que el arte de vanguardia es un soplo de vida en un mundo aburrido y viejo; luego añade, siguiendo su razonamiento aristocrático: es un arte de minorías porque elude la representación y exige ser disfrutado con jocosa intrascendencia (Ortega y Gasset, 2000; Urrutia, 2006). 
El argumento de la "vitalidad" sigue siendo crucial para explicar la función social del arte en la sociedad contemporánea. Boris Groys (2005), un reconocido estudioso del tema en el presente, considera que la afirmación de "lo nuevo" -en su doble acepción de lo único y lo último- define el papel social primordial del arte. Mediante este compromiso vital, y regenerador de la sociedad, el arte, en la actualidad, acepta renunciar a su autonomía en aras de convertirse en una pujante fuerza de innovación en todos los ámbitos de la sociedad. La curiosa paradoja de este cambio reside en que para poder innovar hace falta conservar el pasado y las instituciones (academias, museos, bibliotecas, etc.) que lo atesoran, ¿cómo si no se demostraría que algo es nuevo? La novedad como finalidad del arte y la impostura del artista, excéntrico y en continua rebeldía, sin escuela ni movimiento que lo represente porque cada artista se debe a sí mismo (Krauss, 1996, 209), produce, más que la amenaza al orden establecido, su conformidad, sobre todo con la expansión de la cultura de masas. Haga lo que haga el arte, su mensaje no deja de ser individualista, tanto en la acción como en la interpretación, además de en clave de fantasía. Su planteamiento parece decir: jatrévete a probar la libertad, aquí no te pasará nada! Por ello, Adorno y Horkheimer (2002) criticaron las industrias culturales desde sus comienzos a mediados del siglo xx como manipuladoras de opinión, entre otras razones porque consideraron que en su fundamento está la confusión entre la copia y el original y la devaluación de la cultura a la condición de espectáculo, dominado por las leyes del mercado (2002, 174).

Con el paso del tiempo, la amplia difusión de la cultura de masas a nivel mundial ha propiciado un continuo tránsito entre el arte culto y popular. Hasta cierto punto, la dicotomía a la que alude Pierre Bourdieu entre el arte "puro", que cultivan las clases cultas, definido por su forma y el arte "real", de las clases populares, definido por el contexto aparece difuminada (Bourdieu, 1979, 4). La realidad, no obstante, es más compleja que sus apariencias, a los presupuestos de "distinción" y fragmentación de la cultura en términos de clase social no cesan de añadirse otras variables, hasta ahora descuidadas, como la edad, el género o el territorio. No se ha creado, pues, una única cultura de masas al gusto de todos. Los artistas, los públicos y los espacios en que se vivencia el arte (las artes) siguen siendo en muchos sentidos marcadamente distintos. Ni siquiera en la música (el arte de masas por excelencia), donde la fusión de lo culto y lo popular, de lo cercano y lo "exótico", está siendo extrema se ha logrado unificar las inagotables y posibles diferencias de patrones musicales. Un ejemplo paradigmático de esta amalgama, ampliamente criticada por los estudiosos de la etnomusicología, es la World-Music, un pretendido "folklore del mundo" de diseño, creado a base de combinar sonoridades del mundo en un formato al gusto de Occidente (Giannattasio, 2000).

La hibridación, siguiendo el término de García Canclini, de las artes y de las culturas (en sentido antropológico) y el fin de la autonomía del arte, tal como se ha discutido en este artículo, crean conjuntamente una dinámica de homogeneización de la cultura, pero también inversamente de creación de identidades pretendidamente 
"puras". La erosión de los límites del arte por la influencia de la sociedad ha ocurrido desde dentro, como dinámica propia de disolución y fusión interna del mundo del arte. En este sentido, cabe citar el ejemplo del movimiento modernista, su fascinación por la cultura popular y exótica; su voluntad de experimentar en favor de la obra de arte abierta, sin creador ni espectador en el sentido tradicional. Merced a estas y otras experimentaciones el universo del arte creció fuera de sus confines y a expensas de la realidad, de la misma manera que la realidad ingresó de lleno en su mundo interior. A consecuencia de todo ello, si tomamos por ejemplo la música clásica contemporánea, la revolución en su significado (eso que llamamos música) ha sido total y absoluta; después de todo, como afirma el prestigioso compositor alemán Stokhausen: "Todo cuanto vibra hace música" $(1973,9)$.

En las últimas décadas, otro argumento a considerar en cuanto al proceso de disolución de los contornos del arte es la "convergencia tecnológica" (Jenkins, 2008; López Cuenca, 2009). Una dinámica de concentración del capital multimedia en conjunción con la expansión de la tecnología digital global que está logrando la fusión total de las artes, de los medios y de los públicos. ¿Cuáles serán las consecuencias de esta inusitada difusión y deslocalización de la cultura? Para Jenkins, por ejemplo, la interpretación es de exaltado optimismo por la democratización de la "alta cultura", pero para otros autores, críticos con el capitalismo cultural y el monopolio de las Tecnologías de la Comunicación y la Información, lo que se constata es el desaliento por la privatización y expolio del patrimonio cultural en manos de unas pocas multinacionales dueñas del imaginario mundial.

Sin entrar en la polémica devaluación de la cultura por el consumo, George Yúdice sostiene que asistimos a la definitiva disolución del sentido trascendente de la cultura en favor de su utilidad como "recurso" en innumerables campos de interés económico y social, como la tolerancia multicultural, el planeamiento urbano o el turismo sostenible (Yúdice, 2002, cap. 1). Desde su opinión, la nueva legitimidad del arte a la manera de "recurso" obedece a la globalización y al debilitamiento del sentido identitario, conexo a la cultura nacional y local. Abandonada, o cuando menos reducida, la utilidad nacional de la cultura, su interés para el Estado decrece, en cambio, su dimensión económica, tiende a expandirse. En este sentido, el arte se convierte ahora en el eje central de toda la cultura, por lo que curiosamente, como ya hemos explicado, considerar la cultura como sinónimo de arte parece de lo más coherente. En resumen, de acuerdo con Groys y revitalizando el argumento de Simmel sobre el que hemos enhebrado este artículo, el arte como savia de la vida asume un nuevo rol social mucho más pragmático y comprometido con la realidad, deja los museos e irrumpe en todas partes, incluyendo dentro de su manifiesto interés salvar el mundo, ser su energía vital (Groys, 2005, 82-90). Su valor, en efecto, resulta inusitado en todos los ámbitos de la sociedad: como cauce de innovación económica, como proyecto de vida e incluso como ideal de "hacer bien" las cosas, desde la política al trabajo. Vivir con arte y ser artista se convierte en un anhelo compartido por toda la sociedad. 
El arte no sólo es la fuente de innovación por excelencia de la economía global sino su fuente de legitimidad y de vitalidad, sea como "vía de escape" ante el escaso optimismo que se respira (Merriam, 2008), sea como memoria moralizadora contra el terror (Yúdice, 2005), o sea como sentido de comunidad en la distancia (Martínez Berriel, 2008). Ahora bien, en mi opinión, el sentido de utilidad en el arte eclipsa pero no elimina su "viejo" ideal estético. De hecho, su nueva función social se sostiene en el ideal trascendente; habría que decir incluso que ambos significados se necesitan mutuamente, aunque sólo sea como ideal, como referencia simbólica de lo que es la verdad y la perfección. Desde una perspectiva global, es cierto que ya nadie cree en el arte "puro" sin referencia al mercado y que la autonomía del arte definitivamente ha desaparecido; pero desde una perspectiva local (nacional), la excepción cultural no deja de ser un debate en plena y eufórica vigencia. La cultura nacional "elitista" o "popular" como un reducto de espiritualidad no mercantilizable existe y se resiste a sucumbir; otra cosa es que seguramente los días que le quedan sean contados, si prosigue debilitándose el sentido de identidad nacional.

\section{De la NECESIDAD DEL ARTE EN LA SOCIEDAD GLOBAL}

El éxito de una sociedad capitalista global está condicionado a la aceptación de un proyecto de cultura global: planetaria, transnacional y transcultural. Por el momento, se trata de un proyecto ideológico-en su doble acepción de representación colectiva y de ensoñación bienintencionada- de escasa representación colectiva, pero ello no quita para que tenga una indiscutible relevancia social por diversas razones. En primer lugar, porque en contextos transnacionales, como pueden ser las ciudades que lideran la globalización, no existe una referencia nacional (Appadurai, 1997). En segundo lugar, porque la "cosmopolítica" resulta imprescindible dentro del Estado-Nación en sociedades globales y multiculturales (Kymlicka, 1999; Beck, 2006). Y en tercer y último lugar porque dentro de ciertos grupos de élite profundamente implicados en la globalización como los científicos, los artistas y especialmente, como analizaremos al final de este artículo, los músicos, el mundo es ya realmente una patria.

Este proyecto ideológico, por el momento más "imaginativo" que real, no debe interpretarse en el sentido de considerar que la globalización consiga establecer una única cultura. Se sabe que "la cultura es una máquina de crear diferencias" y que la combinación Estado, mercado y sociedad, en sus múltiples interdependencias, produce continuas diferencias culturales (Warnier, 2002, 117). Los esfuerzos que ejerce el mercado en favor de homogeneizar la cultura, aunque portentosos, no consiguen limitar la vitalidad de las culturas locales, sino que con frecuencia la alientan (Feartherstone, 1996). Se puede afirmar por tanto que la resultante de estas tendencias en última instancia es incierta, pero no se puede en todo caso ignorar que la globalización promueve un proceso de acción y convicción de que el mundo es un pequeño y frágil planeta ciberconectado y vigilado en el 
que estamos obligados a convivir sin fronteras y en un continuo intercambio de informaciones, personas y bienes (Virilio, 1997). Este hecho supone un duro golpe al sentido "religioso" que ha mantenido indisolublemente unido al individuo con el medio y con la comunidad al mismo tiempo que remite a una necesaria voluntad de construir un sentido de identidad universal de la humanidad. En este sentido, la globalización alienta e imagina una "Soberanía sin territorialidad", un credo de comprensión universal en el que quepan todas las variadas formas de lealtad y filiación que la movilidad humana y las comunicaciones generan (Appadurai, 1996). Precisamente por ello, aunque se admita la extrema distancia que media entre la realidad y la ideología, y entre el discurso de las élites y el de los pueblos, resulta de vital importancia crear un sentido de cultura universal, sin base territorial, utilizando el arte como principio de entendimiento común, de "simpatía" universal en la acepción estética.

Para calibrar la necesidad del arte en la sociedad global es importante considerar la expansión de la ciudad y del urbanismo a nivel mundial y su repercusión en términos de movimiento y proliferación de espacios simulados y efímeros (Sennett, 1997; Augé, 1987; Koolhaas, 1996). Otro argumento no menos significativo también relacionado con el fenómeno urbano es nuestra condición urbanita de viajeros proclives al cambio y a las identificaciones pasajeras, lo que reflexivamente se traduce en desarraigo (del lugar) y desmaterialización (ampliación del mundo virtual). La misma consecuencia produce la economía capitalista al reducir cuando no eliminar las relaciones personales y habilidades manuales en los procesos productivos (Sennett, 2006) y el predominio de la vasta esfera del consumo incitándonos continuamente a crear nuevos y continuos deseos (Bauman, 1999). Así, las "ciudades globales" en tanto que centros neurálgicos de la globalización son en sí mismas atractivos productos culturales, razón por la que centralizan servicios relacionados directa o indirectamente con el arte. Por el mismo motivo, dan prioridad a los eventos y a los servicios e industrias de entretenimiento que demanda el turismo y los grupos que transitoriamente las visitan. Todo ello se hace patente en el acusado interés del urbanismo global por los auditorios, orquestas y museos como iconos fundamentales de estas ciudades cosmopolitas (Sassen, 1991; Castells, 1995; Ingersoll, 1996; Martínez Berriel, 2008).

Los cambios en la percepción del espacio, en las condiciones de vida y en la propia mentalidad que suscita el capitalismo global hacen del arte un metalenguaje, tan universal y necesario para vivir, construir y comprender la realidad como puede ser, desde otro punto de vista, la ciencia. La movilidad, el marketing y la expansión del espacio virtual a todas las generaciones, incluidos los niños, promueven el desarrollo de la economía de la cultura y el arte. Se requiere además un elevado consumo de arte y artistas como mediaciones fundamentales de nuestra sociabilidad (o soledad) y como artífices de un nuevo y arbitrario espacio interactivo liberado del tiempo real. Por ello, el arte se ha convertido en un principio absoluto de realidad; hasta tal punto, que lo que parece verdad imaginativamente es tan importante o más que lo que es verdad (Bauman, 2001, 128). Se puede por ello afirmar que los 
artistas son la fuerza vital de la sociedad global; no en vano, el actual capitalismo ha sido definido como "capitalismo cultural", porque resulta más importante y rentable crear y vender emociones o ilusiones que no pesan ni ocupan lugar y son fácilmente transformables, que hacer lo propio con inamovibles cosas (Rifkin, 2000).

\section{LA MÚSICA Y LOS MÚSICOS DE ORQUESTA COMO ARTESANOS DE LA GLOBALIZACIÓN}

Son múltiples las razones que hacen de la música el arte esencial de la sociedad global (Martínez Berriel, 2010). De una parte, la música, por su naturaleza evanescente y su capacidad de crear ambientes e identificaciones pasajeras, representa como se ha visto la ideología postmaterialista de las élites transnacionales de la globalización. De otra parte, la música como arte del tiempo, como memoria o como manipulación, por señalar algunas de las profundas e inextricables relaciones que unen a la música con el tiempo, es el modelo por excelencia de convergencia de todas las artes (Ramos Torre, 2010). La explicación fundamental que sintetiza su enorme caudal como base de la sociedad es que donde hay música hay "acontecimiento" (Mitchell, 1972, 78-79). En la actualidad, con más razones que nunca, el sentido de presente compartido que genera la música es una necesidad para el conjunto de la sociedad, teniendo en cuenta su condición "líquida" en la acepción de Bauman (2005). Es un espacio afectivo y "mágico": no tiene confines, ni punto focal privilegiado, además es dinámico y logra conexión sin necesidad de proximidad ni de ocupar un lugar. De ahí su incuestionable y versátil utilidad ¡No se le puede pedir mayor eficacia y adaptabilidad a un espacio! Incluso la arquitectura, el arte sólido por excelencia, pretende renunciar a la permanencia y acercarse al ideal de la música creando espacios sensibles e interactivos.

Escuchar música es la práctica cultural más extendida y diversificada de las sociedades occidentales. Su fácil reproducción y su capacidad de ser escuchada prácticamente en cualquier circunstancia y lugar, sin que requiera precisa atención, hace de ella una suerte de atmósfera que todo el mundo respira. Con la peculiaridad de que admite un consumo muy diferenciado, a la vez que unitario, que va del Ipod al concierto multitudinario. Ninguna otra expresión artística o cultural es comparable en cuanto a apropiación personalizada y diversidad de estilos, gustos o formas de consumo y uso. De ahí su importancia para la sociedad global, como símbolo de unidad y de multiplicidad, de identidad y de identificación momentánea.

Por otra parte, la música es un vehículo privilegiado de emociones, y éstas son más universales y eficaces que las palabras para construir una comunidad especialmente cuando no se comparte una misma lengua (Zeldin, 1997, 163; Frith, 2008, 423). En este sentido, ha sido y continúa siendo indiscutible la funcionalidad de la música como cauce de paz social y tolerancia en sociedades multiculturales por su facilidad para generar entendimiento multicultural e infundir optimismo (Merriam, 2008). A estas idóneas cualidades comunitarias se debe añadir el 
sentido trascendente que la acompaña desde su origen como expresión de "lo inefable" (Jankelevitch, 2005). Su capacidad de llegar más allá del verbo y por tanto más allá de la política ha sido una de las prerrogativas que se han utilizado reiteradamente para teorizar sobre su privilegiada posición como cumbre de la cultura occidental.

Charles Lalo (1908), alumno de Durkheim y uno de los primeros creadores de la estética sociológica, decía con gran sorna, no exenta de razón, que toda la historia de la sociología de la música (hasta llegar a él, que se definía profundamente positivista) podía resumirse en las memorables palabras que recogió Molière en $E l$ burgués gentilhombre en boca de un profesor de filosofía: ¿Si todos los hombres aprendiesen música, no sería éste el mejor medio para comunicarse y ver realizada en el mundo la paz universal? Lamentablemente, tenemos que compartir su repuesta: aunque la música sea el mejor medio de celebrar la paz, no es suficiente para crearla.

\section{LOS MÚSICOS DE ORQUESTAS SINFÓNICAS}

A modo de reconducir los argumentos desgranados a lo largo de este artículo a un estudio empírico que pruebe los argumentos teóricos anteriormente desarrollados, se analiza la experiencia de los músicos de orquestas sinfónicas en España, como ejemplo de un colectivo de vocación universal que asume el ideal de la cultura como perfección y que se identifica de pleno con la música como lenguaje inefable y trascendente. Los argumentos que siguen sintetizan y recontextualizan los resultados de diversas investigaciones sobre la autopercepción de la profesión (Martínez Berriel, 1992, 1993, 2008).

Los músicos de orquestas sinfónicas están en la cima del sistema musical, cuentan con condiciones salariales y de estabilidad de empleo indiscutiblemente mejores que la mayoría de los músicos. Pertenecen al sector de la música "seria" a la que se atribuye un valor cultural y estético, universal e imperecedero del que adolece la música "ligera" o "popular", referida y circunscrita a su contexto y función. Esta inicial jerarquía de la cultura queda patente, incluso, en el vocabulario de la profesión. Los músicos de orquesta ostentan la calificación de "profesores" y sus sesiones de trabajo se califican de "servicios". Ello quiere decir entre otras cosas que la música culta se considera una necesaria instrucción e institución pública que deben patrocinar los Estados, con independencia del interés que suscite en la comunidad, como de hecho ocurre en el caso de la música clásica contemporánea.

La idea de utilidad social y la exaltación de la vocación como principios de la profesión son aspectos esenciales de la cultura de este grupo que favorecen enormemente su integración en un amplio contexto internacional. Los músicos saben que su trabajo nunca puede ser burocrático y que requiere demostrar día a día sus capacidades. De hecho, hasta las orquestas más estables disponen en sus reglamentos de controles de calidad que permiten poner a prueba la destreza 
instrumental a nivel individual como criterio permanente de excelencia. De todas formas ellos están preparados, el "Sacrificio" que supone el persistente estudio solitario desde la más tierna infancia les ha enseñado que su formación es ininterrumpida. Quienes aprenden música saben que nunca se puede dejar de practicar, máxime si se pretende ser "Virtuoso"; ese largo camino de perfección no tiene fin ni, por supuesto, fronteras. El "virtuosismo" que exige el arte musical y la "vocación" que su práctica demanda evocan más intensamente que en otras profesiones su origen trascendente. Por eso en el aprendizaje y ejercicio de la música se manifiestan enormes dosis de misticismo. El "maestro" que dirige la orquesta o que enseña el instrumento ocupa en la formación de los músicos un lugar comparable al de un guía espiritual. Inculca un dogma inamovible: "con la música no se puede nunca mentir", para hacer música hay que sentirla, de lo contrario se nota. En todas las orquestas, la organización jerárquica del trabajo es un principio indiscutible, aunque su fundamento sea de orden práctico: el grupo está por encima del individuo. Sólo el Director, el "Maestro", interpreta las partituras y hace vibrar a la orquesta como un único instrumento. Su poder es realmente absoluto e individual, pero se lo otorga la orquesta.

Los músicos de orquesta constituyen una comunidad particularmente sensible a la idea de promover derechos universales. El reconocimiento intrínseco de la profesión acerca del valor absoluto del arte, sin otra consideración ajena al mismo, es un claro principio de justicia universal. Como es lógico, esta reivindicación contra los privilegios u obligaciones nacionales o territoriales la hace suya un colectivo "artesano", de vida frecuentemente nómada, que considera su propio trabajo como una pasión en la que se combina la realización individual con la hermandad de la humanidad. De ahí el profundo orgullo sentimental y trascendente del oficio por encima de todo interés económico que se demuestra en diversos estudios sobre esta profesión (Clanche, 1990; Faulkner 1973; Martínez Berriel, 1992).

Seguramente, la expresión "ir con la música a otra parte" ha quedado en el lenguaje común como una reminiscencia del pasado en que los músicos aún juglares se desplazaban de sitio en sitio y de ciudad en ciudad llevando con la música la crónica de la vida. Mucho ha cambiado la profesión y otro tanto se ha diversificado y especializado; sin embargo, esta característica pervive bajo otras formas. En el ámbito de la música clásica, casi todas las orquestas del mundo están formadas y dirigidas por músicos extranjeros de todo el mundo, hay oposiciones libres y un margen importante de movilidad. Las cifras varían enormemente según la tradición musical del país de referencia, pero esta particularidad de la profesión es incluso apreciable en un país tan intensamente educado en la música clásica como Alemania (Martínez Berriel, 1992). En España según datos actuales de la Asociación Española de Orquestas Sinfónicas (AEOS, 2010), la proporción de extranjeros en las 29 agrupaciones existentes en España varía entre el 60\% y el 80\% de las plantillas formadas por 60-80 músicos cada una, siendo la Orquesta Sinfónica de Barcelona la que tiene una proporción más baja (46\%) y la Orquesta Sinfónica de Sevilla la más alta (85\%). La dispersión geográfica nacional e internacional es amplísima 
en todos los casos. La Orquesta Filarmónica de Gran Canaria está formada por músicos procedentes de América del Norte y del Sur: Estados Unidos, Canadá, Cuba, Venezuela y Argentina; de Europa Occidental: Alemania, Italia, España, Dinamarca, Holanda y Reino Unido; y de Europa del Este: Rusia, Polonia, Hungría, Rumanía, Eslovenia, República Checa, Croacia y Serbia (Martínez Berriel, 2008).

Se puede afirmar que la movilidad es consustancial tanto a la formación como a la profesión de músico; el lenguaje musical permite trabajar sin ninguna referencia territorial, el mercado de trabajo es internacional y los repertorios y audiciones de las orquestas sinfónicas son prácticamente idénticos en todo el mundo. Por eso en la profesión se dice que para ser un buen músico conviene ser célibe, ya que sin familia es más fácil cumplir las rigurosas exigencias que comporta la profesión en cuanto disciplina y en cuanto a la independencia que requiere la vida itinerante.

Al analizar la impecable imagen de una orquesta sorprende cómo tanta movilidad y diversidad permite una organización del trabajo única y eficaz. Una de las claves es el profundo "respeto" que entraña el trabajo artesanal, siempre mejorable y admirable (Sennett, 2003, 98). Por encima de todas las diferencias la música suena con rotunda unicidad. La magia de este resultado radica en que los músicos son, por encima de todo, músicos en el sentido de "mediaciones" de un acontecimiento ("evenement") compartido que transcurre en ese preciso momento (Hennion, 2003). Lo que quiere decir que por encima de todo aman la música y se sienten satisfechos por tocar juntos y comunicarse entre ellos y con quienes les escuchan. Por eso, entienden su profesión en modo inseparable como una forma de amor y de vida.

Los músicos, cuando actúan, ponen a prueba sus capacidades, se entregan con una intensidad y concentración absolutas, considerando, porque así es materialmente, que es la vida lo que dan. Consiguen vibrar juntos porque son trabajadores del tiempo, educados con el metrónomo para ser rigurosamente exactos, puntuales y metódicos; saben que en su arte el tiempo lo es todo y el silencio, el más puro de los sonidos. La extrema identificación de los músicos con el instrumento que tocan y con la música como un todo se corresponde con la intensa cualidad artesanal y mística del oficio. En este sentido, los músicos responden al estereotipo romántico de identificar la música con la vida. El resultado de todo ello se manifiesta en dos aspectos muy marcados en la profesión, que denotan el extremo solapamiento entre la vida privada y la profesión. Por un lado, la intensa transmisión hereditaria de la afición y la profesión, manifiesta en muchos casos a lo largo de sucesivas generaciones y de familias enteras dedicadas a la música. Y, por otro, la no menos intensa endogamia de la profesión (Martínez Berriel, 1993).

El abigarrado mundo de relaciones personales y afectivas que envuelven el quehacer musical, unido al hecho de que se trata de un trabajo intensamente colectivo, favorece sin duda el hecho de que los músicos sean un grupo ejemplar en la construcción de la ciudadanía universal. Por lejos que vayan encuentran un mismo ambiente cosmopolita y familiar. Por eso no les importa tanto el lugar donde actúan como el hecho de hacer música. El comentario de un violonchelista 
eslovaco de la Orquesta Filarmónica de Gran Canaria es muy representativo de esta manera de pensar: "Yo nací en una ciudad, y en la ciudad no hay más tierra que la del parterre. Cuando eres de una ciudad eres de cualquier ciudad. Mi tierra está en mi parterre" (Martínez Berriel, 2008).

\section{CONCLUSIÓN}

Desde el punto de vista de la cultura trascendente, el arte, y la música más particularmente en la medida que transcurre en el tiempo, es un contenedor de eternidad, un espacio sagrado en el que reside el tiempo, detenido e intacto para volver a empezar, como si nunca hubiera tenido lugar. El Tiempo, otros tiempos, otros lugares, aparecen una y otra vez renovados. Gracias a esta condición "vital" y sentimental, la música despierta una intensa identificación, lo que resulta primordial para el conjunto de la cultura en términos de educación, innovación y de "Convergencia cultural" a nivel mundial. En su condición de acontecimiento y, por tanto, de significado presente y nunca acabado, sujeto a la experiencia viva que suscita en el receptor y en la comunidad que genera, la contribución de la música resulta fundamental para imaginar y hacer realidad la construcción de la sociedad global. La música y el arte en general se presentan como el más inclusivo de los medios para promover este proyecto universal: se siente y gusta, implica simultáneamente conocimiento y sentimiento, de ahí su enorme eficacia real e imaginativa en aras de la convivencia mundial. Los músicos, por la extrema identificación entre trabajo y vida, educados en la armonía y creadores de ella son el colectivo más avanzado en el proyecto de hacer del mundo un lugar sin fronteras; son ellos, en propiedad, los embajadores del ideal ético y estético de la perfección que promovieron los poetas-filósofos románticos con Schiller a la cabeza. En conclusión, la sociedad global puede definirse como la sociedad del arte y por este motivo, precisamente, los artistas asumen un notable protagonismo en la vida social como representantes de ese proyecto universal.

\section{REFERENCIAS BIBLIOGRÁFICAS}

Adorno, Th. y Horkheimer, M. (2004) Dialéctica de la Ilustración. Madrid, Trotta.

Augé, M. (1987) Los no lugares. Una antropología de la sobremodernidad. Barcelona, Gedisa.

ARENDT, H. (2005) La condición humana. Barcelona, Paidós.

APpaduraI, A. (1999) Soberanía sin territorialidad. Notas para una geografía postnacional. Nueva Sociedad, 163, 109-124.

Asociación EspaÑola de OrQuestas Sinfónicas (2011). Consultado el 18 de octubre de 2010. http://www.aeos.es.

BhabHa, H. (1994) The location of culture. London/NY, Routledge.

Bauman, Z. (1999) La globalización. Consecuencias humanas. México, Siglo XXI. 
ARTE, MÚSICA Y PERFECCIÓN EN LA SOCIEDAD GLOBAL

- (2001) El arte postmoderno o la imposibilidad de la vanguardia, en La postmodernidad y sus descontentos. Madrid, Akal.

- (2005) Modernidad liquida. México, Fondo de Cultura Económica.

BELL, D. (1977) Las contradicciones culturales del capitalismo. Madrid, Alianza.

BECK, U. (2006) La mirada cosmopolita o la guerra es la paz. Barcelona, Paidós.

BouRdieu, P. (1979) La distinction, critique sociale du jugement. Paris, Minuit.

CASTElls, M. (1995) La ciudad informacional. Tecnologias de la información, estructuración económica y el proceso urbano-regional. Madrid, Alianza.

Clanche, F. (1990) Les musiciens profesionnels des orchestres clasiques. París, Memoire du D.E.A. Université Paris X.

Cuché, D. (1998) La noción de cultura en las ciencias sociales. Buenos Aires, Nueva Visión.

De ClERCQ, J. (1970) La profession de musicien. Une enquête. Bruselas, Institut de Sociologie.

EAgleton, T. (2001) La idea de la cultura. Una mirada politica sobre los conflictos culturales. Barcelona, Paidós.

ELIAS, N. (1987) El proceso de la civilización. Investigaciones sociogenéticas y psicogenéticas. México, Fondo de Cultura Económica.

FAulkner, R. (1973) Carreer Concerns and Mobility Motivations of Orchestra Musicians. The Sociological Quarterly, 14, 141-157.

FeAtherstone, M. (1996) Localism, globalism and cultural identity, en Wilson, R. y DissanaYAKE, W. (eds.) Global/Local. Cultural Production and the Transnational Imaginary. Londres, Duke University Press, 46-77.

Frith, S. (2008) Hacia una estética de la música popular, en Cruces, F. y otros (eds.) Las culturas musicales. Lecturas de etnomusicología, 413-435.

García Canclini, N. (2003) Noticias recientes sobre la hibridación. Revista Transcultural de Música, n.ำ 7, 1-12.

- (2012) La globalización: ¿productora de culturas híbridas?, en El mensaje es el medio (blog), octubre. http://elmensajeeselmedio.blogspot.com.es

Gellner, E. (1992) El arado, la espada y el libro. La estructura de la historia humana. México, Fondo de Cultura Económica.

Giannattasio, F. (2000) L'esthétique e(s)t le marché: quelques réflexions sur le comerce de la world music. Transcultural Music Review, 5. Consultado el 9 de diciembre de 2012. http://www.sibetrans.com/trans/a241/lesthetique-est-le-marche-quelques-reflexionssur-le-commerce-de-la-world-music.

Giner, S. (2005) La consagración de lo profano, en Roche, J. A. y Oliver, M. (eds.) Cultura y globalización. Entre el conflicto y el diálogo. Publicaciones Universidad de Alicante, 225-251.

Groys, B. (2005) Sobre lo nuevo. Ensayo de una economía cultural. Valencia, Pre-Textos.

Hell, V. (1986) La idea de cultura. México, Fondo de Cultura Económica.

Heinich, N. (2001) Sociología del arte. Buenos Aires, Nueva visión.

Hennion, A. (2002) La pasión musical. Barcelona, Paidós.

IngERSOLL, R. (1996) Tres tesis sobre la ciudad. Revista de Occidente, 185, 11-44.

INGLEHART, R. (1991) El cambio cultural en las sociedades avanzadas. Madrid, CIS.

Jankelevitch, V. (2005) La música y lo inefable. Buenos Aires, Alpha Decay.

JENKIns, J. (2008) Convergence Culture: La cultura de la convergencia de los medios de comunicación. Barcelona, Paidós.

KoolHaAs, R. (1996) ¿Qué fue del urbanismo? Revista de Occidente, 185, 5-10. 
Krauss, R. E. (1996) La originalidad de la vanguardia y otros mitos modernos. Madrid, Alianza.

KYMlicka, W. (1996) Ciudadanía multicultural. Barcelona, Paidós.

LALO, Ch. (1908) L'estetica sociológica e l'arte musicale, en SERraVEzzA, A. La sociología della musica, 1980. Turín, EDT, 55-65.

LASH, S. (2003) Lebenssoziologie (sociología de la vida/vitalista: Georg Simmel en la era de la información. Estudios Sociológicos, vol. 21, 63, 523-540.

Latour, B. (1993) Nunca hemos sido modernos. Madrid, Debate.

LENOIR, F. (2003) Las metamorfosis de Dios. La nueva espiritualidad occidental. Madrid, Alianza.

López Cuenca, J. (2009) Artes visuales y convergencia tecnológica. Revista de Occidente, 333, 36-49.

Luque Baena, E. (1974) Del conocimiento antropológico. Madrid, CIS, 1974.

- (2004) La polémica ubicuidad de la cultura. Revista de Libros, 93.

MAFFESSOLI, M. (1997) Elogio de la razón sensible. Una visión intuitiva del mundo contemporáneo. Barcelona, Paidós.

MarTínez BerRiel, S. (1992) Los músicos de orquesta: un análisis sociológico de la profesión a través de los músicos. Revista de Musicología, vol. xv, 1, 303-311.

- (1993) La armonía y el ritmo de una ciudad. Las Palmas de Gran Canaria, Servicio de publicaciones de la ULPGC.

- (2008) Elites migratorias transnacionales: los músicos de orquestas clásicas en España. Revista Transcultural de Música/Transcultural Music Review, 12. Consultado el 4 de noviembre de 2012. http://www.sibetrans.com/trans/a101/elites-migratorias-transnacionales-los-musicos-de-orquestas-clasicas-en-espana.

- (2011) El género de la música en la cultura global. Revista Transcultural de Músical Transcultural Music Review, 15. Consultado el 4 de noviembre de 2012. http://www. sibetrans.com/trans/pdf/trans15/trans_15_24_Martinez_Berriel.pdf.

Merriam, A. P. (2008) La música como cultura. Usos y funciones, en Cruces, F. y otros (eds.) Las culturas musicales. Lecturas de etnomusicología. Madrid, Trotta, 275-297.

Mitchell, D. (1972) El lenguaje de la música moderna. Barcelona, Lumen.

Moreno, I. (2005) Globalización y cultura, en Roche, J. A. y Oliver, M. (eds.) Cultura y globalización. Entre el conflicto y el diálogo. Alicante, Publicaciones Universidad de Alicante, 65-87.

NeTtL, B. (2008) Últimas tendencias en etnomusicología, en CrucEs. F. y otros (eds.) Las culturas musicales. Lecturas de etnomusicología. Madrid, Trotta, 115-154.

Ortega y Gasset, J. (2000) La deshumanización del arte y otros ensayos de estética. Madrid, Alianza.

POLANYI, K. (2001) La gran transformación. Los origenes políticos y económicos de muestro tiempo. México, Fondo de Cultura Económica.

Ramos Torres, R. (2000) Simmel y la tragedia de la cultura. Revista Española de Investigaciones Sociológicas, 89, 37-72.

- (2010) Culturas del tiempo: música y sociedad a principios del siglo XX, en Noya, J.; Del Val, F. y Pérez Colman, M. (coords.) Musyca: música, sociedad y creatividad, 259273.

Ramírez, J. A. (1998) Historia y Crítica del Arte. Madrid, Cromoimagen (FCM).

Rifkin, J. (2000) La era del acceso, la revolución de la nueva economía. Barcelona, Paidós. 
ARTE, MÚSICA Y PERFECCIÓN EN LA SOCIEDAD GLOBAL

Sassen, S. (1991) The global city, New York, London, Tokyo. Princeton, Princenton University Press.

Sennett, R. (1997) Carne y Piedra. El cuerpo y la ciudad en la civilización occidental. Madrid, Alianza.

- (2003) El respeto. Sobre la dignidad del hombre en un mundo de desigualdad. Barcelona, Anagrama.

- (2006) La cultura del capitalismo. Barcelona, Anagrama.

SERravezzA, A. (1980) La sociología della musica. Torino, EDT.

Simmel, G. (1986) De la esencia de la cultura, en El individuo y la libertad. Ensayos de crítica de la cultura. Barcelona, Península.

- (2000) La trascendencia de la vida. Revista Española de Investigaciones Sociológicas, 89, 297-313.

Steiner, G. (2007) Nostalgia del absoluto. Madrid, Siruela.

StockHAusen, K. (1973) La música contemporánea. Barcelona, Salvat.

Urrutia, J. (2006) Vitalidad de la deshumanización del arte. Revista de Occidente, 300, 5-10.

VIRILIO, P. (1997) Un monde surexposé: fin de l'histoire ou fin de la geographie? Le Monde Diplomatique, 8, 17-24.

WARNIER, J. P. (2002) La mundialización de la cultura. Barcelona, Gedisa, 2002.

WiLDE, O. (1983) El retrato de Dorian Gray. Barcelona, Planeta.

Williams, R. (1976) Culture, en Keywords: A Vocabulary of Culture and Society. London, Fontana, 76-82.

Yúdice, G. (2002) El recurso de la cultura. Usos de la cultura en la era global. Barcelona, Gedisa.

- (2005) El terror en la cultura global. Clarín, suplemento cultural, 27.

ZELDIN, Th. (1997) Historia intima de la bumanidad. Madrid, Alianza.

Zolberg, V. (2002) Sociología de las artes. Madrid, Fundación Autor/sGAE. 